\title{
ITINERÁRIOS DE LEITURA NA CONTEMPORANEIDADE: PEDAGOGIAS E PRÁTICAS LEITORAS NA CULTURA DIGITAL
}

\author{
CONTEMPORARY READING ITINERARIES: READING \\ PEDAGOGIES AND PRACTICES IN DIGITAL CULTURE
}

\author{
Sarah Suzane BERTOLLI ${ }^{1}$ \\ Alexandre Ferreira da COSTA ${ }^{2}$ \\ Agostinho Potenciano de SOUZA ${ }^{3}$
}

\begin{abstract}
Resumo: Este trabalho tem por tema a leitura no cenário da educação brasileira contemporânea, partindo da análise dos discursos didático-normativos e das práticas de linguagem em sala de aula vinculadas à educação básica. Objetiva-se verificar quais práticas para a formação de leitores são sugeridas nos documentos do Ministério da Educação (MEC) que norteiam o currículo e a prática docente. Para realizar este estudo, consideramos o objeto em sua perspectiva histórica e discursiva, refletindo sobre as transformações e regularidades dos conteúdos, estratégias, práticas, habilidades e expectativas de aprendizagem da leitura na escola, tendo em vista o recorte temporal dos Parâmetros Curriculares Nacionais (PCN, 1997) até a Base Nacional Comum Curricular (BNCC, 2017), com análise documental e também revisão bibliográfica desse tema, à luz das teorias de Chartier $(1999,2011,1988)$, Bakhtin $(1979,2011)$ e Rojo (2012). Constatamos que nessa contemporaneidade digital, na qual estamos imersos, a leitura está atrelada à perspectiva dos multiletramentos, e sua práxis pedagógica é enunciada em normativas partindo de teorias do texto e do discurso, as quais serão reconhecidas na BNCC, ainda que não estejam, nesse documento, devidamente creditadas. Concluímos que as práticas leitoras na cultura das tecnologias da comunicação e da informação tendem a ser mais fluidas, embasadas não em procedimentos estanques, mas em itinerários possíveis, aludindo à navegação - metáfora e também nomeação da leitura em rede, ou seja, realizada na internet.
\end{abstract}

Palavras-chave: Leitura. Ensino. Discurso. Multiletramentos.

Abstract: This paper addresses reading in the Brazilian contemporary education scenario, starting from the analysis of didactic-normative discourses and classroom practices related to basic education. The objective is to verify which reader formation practices are suggested in the Brazilian Ministry of Education documents that guide curriculum development and teaching practices. Based on Chartier (1999, 2011, 1988), Bakhtin $(1979,2011)$, and Rojo (2012), the object was taken in its historical and discursive perspective and considered the transformations and regularities of contents, strategies, practices, abilities and expectations of reading learning at school, in view of Brazilian curricular guidelines (PCN, 1997; BNCC, 2017). Results point that, in this digital culture in which we are immersed, reading is tied to the perspective of multiliteracy, and its pedagogical praxis is enunciated in regulations based on text and discourse theories that can be recognized in $\mathrm{BNCC}$, though not directly stated. It is argued that reader practices in this culture of new communication and information technologies tend to be more fluid, based not on closed procedures, but on possible itineraries, alluding to navigation as a metaphor and a way of naming network reading.

Keywords: Reading. Teaching. Speech. Multiliteracies.

\footnotetext{
${ }^{1}$ Universidade Federal de Goiás. Doutoranda do Programa de Pós-graduação em Letras e Linguística da UFG. Email: sarah.goncalves@ifgoiano.edu.br

${ }^{2}$ Universidade Federal de Goiás. Docente do Programa de Pós-graduação em Letras e Linguística da UFG. Pósdoutor em Linguística pela UnB. Doutor em Linguística Aplicada pela Unicamp. E-mail: alexandrecostaufg@gmail.com

${ }^{3}$ Universidade Federal de Goiás. Docente do Programa de Pós-graduação em Letras e Linguística da UFG. Doutor em Estudos Linguísticos pela UFMG. E-mail: apotenciano20@gmail.com
} 


\section{Considerações iniciais}

Este trabalho parte da complexidade de definição e compreensão de uma prática contemporânea que é a "leitura de navegador", ou seja, o modo de ler na rede, na cultura digital, e do questionamento sobre o modo como ("ou se") a escola brasileira lida com a atualização dessa atividade linguística. Considerando o papel do leitor diante de um texto e a aparente liberdade que esse sujeito possui quanto à realização dessa leitura, compreende-se que há, entretanto, “(...) limitações derivadas das capacidades, convenções e hábitos que caracterizam, em suas diferenças, as práticas de leitura" (CHARTIER, 1999, p. 77). Assim, este estudo busca investigar a noção de leitor nestes tempos, à luz de teóricos que problematizam o tema pelos prismas histórico e discursivo.

As inquietações que emergem de tal problemática de pesquisa são as seguintes: como (e se) a escola básica no Brasil se apropria das práticas de leitura no meio digital? Na contemporaneidade, o ensino da leitura se mantém em práticas tradicionais estanques ou permeia diversos campos de atividade humana? Está a escola básica inserida no viés pedagógico dos multiletramentos no ensino da leitura? Quais práticas compõem os itinerários de um leitor-navegador?

O necessário recorte temporal desta pesquisa, importante para compreender como a leitura tem sido oportunizada na escola básica no Brasil, partirá do advento dos Parâmetros Curriculares Nacionais (PCN, 1997) e alcançará a proposta de implementação da Base Nacional Comum Curricular (BNCC, 2017). Essa escolha se deve ao fato de os PCN inaugurarem no País um movimento de ensino da Língua Portuguesa de viés discursivo, com explanação de estratégias e práticas leitoras para a formação de alunos que adquiram o hábito da leitura (MARCUSCHI, 2008).

Para essa análise, buscamos os estudos de Chartier (1999, 2011, 1988), para construir um breve caminho histórico das práticas de leitura, considerando o perfil do leitor ao longo do tempo, com as mudanças dos suportes e também das finalidades da leitura. Diante dessa contextualização, a voz de Bakhtin (2011) ecoa, já que é oportuno analisar a conjuntura desse sujeito construído sócio-historicamente - o leitor da contemporaneidade - partindo dos estudos do filósofo da linguagem, sobretudo de sua pesquisa sobre gêneros discursivos. A perspectiva de letramentos - ou melhor, multiletramentos ${ }^{4}$ - também é considerada, tendo em vista que as

\footnotetext{
${ }^{4}$ Mais adiante, neste trabalho, constará essa mudança de viés com a conceituação de letramento e multiletramentos. Revista Graphos, vol. 21, n 1, 2019 | UFPB/PPGL | ISSN 1516-1536
} 
exterioridades midiáticas e o contexto escolar fornecem diversas estratégias afinadas com o sujeito-leitor destes tempos.

A metodologia da pesquisa consiste em levantamento bibliográfico e crítica documental das citadas normativas do MEC, com efeito comparativo entre elas. Porém, mesmo diante desse propósito, contamos neste estudo com um exemplo de prática leitora na contemporaneidade digital, encontrada no blog "Notas sobre uma Escolha", percebida pelos comentários que constam nesse suporte, cujo entrelaçamento de olhares leitores (res)significou o texto, pluralizando a compreensão e demonstrando, na prática, a fluidez dos novos tempos também nesse eixo. Para interpretação dos dados, partiremos da análise dos textos e dos discursos indicados, considerando não somente sua materialidade, mas também sua inserção sóciohistórica do corpus levantado.

Pesquisas recentes abordaram o tema da leitura (CORSI, 2017; NOGUEIRA, 2017 e SOUSA, 2016), demonstrando uma preocupação em pensar em habilidades requeridas do leitor contemporâneo. Este estudo se difere deles, entretanto, por situar-se num contexto político diferente, com o advento de um redimensionamento normativo que pretende nortear o currículo e as práticas docentes. A hipótese é que, diante da contemporaneidade digital, é preciso pensar em itinerários de leitura - pois, mais que estratégias, o "leitor-navegador" requer algo mais fluido, líquido, amplo e plural nesses caminhos a serem percorridos. Prova disso é o modo de ler no suporte digital, cuja configuração hipertextual estabelece roteiros "multi” de navegação, o que também se afina com a pedagogia dos multiletramentos. Em embate com as práticas tradicionais de ensino, esses itinerários demonstram como é preciso manter coerências entre sujeitos e práticas no ensino da língua.

Conforme consta no sítio de apresentação da proposta, a Base "abre uma nova fase na educação brasileira" (BRASIL, 2017, s/n), e, tendo caráter normativo, é um documento que precisa ser investigado. Compreender e analisar as ressonâncias da implementação da BNCC, assim como observar as transformações e as regularidades da proposta em comparação com outros documentos do MEC sobre a leitura, é importante para perceber outras nuances do contexto histórico em que vivemos. É preciso questionar que sujeito-leitor é esse que se pretende formar, qual a concepção de leitura presente nas normas e como se faz a didatização desse tipo de leitura. Assim como sujeitos-leitores da contemporaneidade, de variadas idades, têm mudado diante do advento das tecnologias da comunicação e da informação em diferentes esferas sociais, o sujeito da escolarização também mudou e agora é preciso pensar, no viés dos multiletramentos, quais serão os itinerários desse leitor. 


\section{A leitura e o leitor: uma história de práticas}

De Certeau (1994), corroborando o pensamento de Foucault (2006) a respeito das formas de controle do discurso, analisa a leitura como uma prática envolta na ordem do discurso ao explicar que "ler é peregrinar por um sistema imposto" (DE CERTEAU, 1994, p. 264), pois o sistema disciplina, normatiza, controla, didatiza; entretanto, ainda que imerso nessas coerções, o ato de ler pode ser capaz de burlar esse sistema, considerando que

os leitores são viajantes; circulam nas terras alheias, nômades caçando por conta própria através dos campos que não escreveram, arrebatando os bens do Egito para usufruí-los. A escritura acumula, estoca, resiste ao tempo pelo estabelecimento de um lugar e multiplica sua produção pelo expansionismo da reprodução (DE CERTEAU, 1994, p. 269-270).

Sendo o leitor esse viajante ousado, a liberdade pode ser adquirida e "a criatividade do leitor vai crescendo à medida que vai decrescendo a instituição que o controlava" (DE CERTEAU, 1994, p. 267). De Certeau (1994), em alusão histórica, nos recorda como na Idade Média, no contexto religioso, os leitores não tinham autonomia, recebiam o texto e não lhes era dado o poder de ressignificá-lo; eles não eram construtores de sentidos daquele texto religioso, mas reproduziam o que aprendiam do outro a respeito daquela leitura.

Chartier (1999, p. 13), também perseguindo essa história, defende que a leitura é uma "prática encarnada em gestos, espaços e hábitos", e dessas determinações que conduzem as práticas "dependem as maneiras pelas quais os textos podem ser lidos - e lidos diferentemente por leitores que não dispõem das mesmas ferramentas intelectuais, e os que não mantêm uma mesma relação com o escrito" (CHARTIER, 1999, p. 13). Partindo da revisão documental das normas e parâmetros curriculares do MEC, anunciamos as concepções e práticas leitoras (im)postas aos docentes e discentes da escola básica brasileira, cuja base progressivamente se alinha com os objetivos econômicos do Estado e com a lógica do capital. O que se pretende compreender é, principalmente, o que essa nova ordem do discurso na educação do Brasil inaugura quanto à leitura e à formação do leitor. A respeito desse princípio de ordenamento, Foucault simula um diálogo inusitado entre o desejo e a instituição, cuja trama "anima" as relações de objetivação e subjetivação:

O desejo diz: "Eu, eu não queria ter de entrar nessa ordem arriscada do discurso; não queria ter de me haver com o que tem de categórico e decisivo; gostaria de que fosse ao meu redor como uma transparência calma, profunda, indefinidamente aberta, em que os outros respondessem à minha expectativa, e de onde as verdades se elevassem, uma a uma, eu não teria senão de me deixar levar, nela e por ela, como um destroço feliz". E a instituição responde: "Você não tem por que temer começar; estamos todos aí para lhe mostrar que o discurso está na ordem das leis, que há muito tempo se cuida de sua aparição; que lhe foi preparado um lugar que o honra, mas o desarma; e que, 
se lhe ocorrer ter algum poder, é de nós, só de nós, que lhe advém". (FOUCAULT, 2006, p. 7).

Nesse embate, é o desejo que é controlado e vigiado pela instituição. No contexto escolar, não é a predileção do aluno, sua autonomia leitora que guiam as práticas, mas a escola que o disciplina e normatiza o que ler e como ler.

Sabe-se que, "nas relações sociais capitalistas, em que a consciência é considerada superior à prática, ocorre todo um processo dicotômico de separação entre o intelectual e o manual, criando indivíduos que atuarão de forma distinta na sociedade" (GARCIA, 2017, p. 22). Nos últimos tempos ${ }^{5}$, houve um esforço do MEC na difusão de ideias promotoras da formação técnica como interessante à inserção do aluno no mercado de trabalho. Convém estarmos alerta, já que

assim como na sociedade capitalista os produtos do trabalho humano são produzidos não em função de sua "utilidade" mas em função da troca, o que interessa, do ponto de vista educativo, não é o que seja de interesse dos que se educam, mas do mercado. Neste contexto o ato educativo, definido como uma prática eminentemente política e social, fica reduzido a uma tecnologia educacional (FRIGOTTO, 1989, p. 67).

Portanto, a suspeita que temos é de que a instituição escolar submetida "aos interesses e demandas capitalistas reduz a prática escolar a um fator de produção, a um valor econômico e, desta forma, adquire um papel crucial na condução de estratégias para o desenvolvimento econômico" (GARCIA, 2017, p. 49). Mas, e em relação ao desenvolvimento do aluno enquanto leitor? Essa é outra inquietação e uma pergunta que nos conduz a buscar qual é o espaço destinado à leitura nessa nova conjuntura, bem como analisar que leitura é essa e como ela será ensinada. Certamente, respostas mais nítidas a essas indagações serão progressivamente construídas por ocasião da consolidação da BNCC e pela estabilização político-educacional do nosso País, contexto que almejamos ter em breve.

Diante de tal cenário, a escola expressa mais uma vez a dualidade da educação e, por que não dizer, da sociedade e do projeto político a que estamos sujeitos, considerando que a educação básica parece atuar de maneira distinta, pois para a elite "[...] assume caráter propedêutico, a ser complementada com formação científico-tecnológica e sócio-histórica avançada. Para os demais, assume o caráter de preparação geral que viabiliza treinamentos aligeirados [...]" (KUENZER, 2007, p. 116).

\footnotetext{
${ }^{5}$ Reportamo-nos à massiva propaganda do governo para convencer a população brasileira das vantagens de uma formação voltada ao mercado de trabalho. Publicidade televisiva e pela internet, como a que pode ser conferida neste vídeo: https://www.youtube.com/watch?v=HJdL4oNebRs. Acesso em 02 ago. 2018.
} 
Além disso, a instituição se pauta pela letra da lei, por isso o que está normatizado e o que é didatizado precisam de investigação, pois

as percepções do social não são de forma alguma discursos neutros: produzem estratégias e práticas (sociais, escolares, políticas) que tendem a impor uma autoridade à custa de outros, por elas menosprezados, a legitimar um projecto reformador ou a justificar, para os próprios indivíduos, as suas escolhas e condutas [...]. As lutas de representações têm tanta importância como as lutas econômicas para compreender os mecanismos pelos quais um grupo impõe, ou tenta impor, a sua concepção do mundo social, os valores que são os seus, e o seu domínio (CHARTIER, 1988, p. 17).

No contexto de compreensão da realidade social, é importante considerar que "o discurso é constituído pela diferença entre o que poderíamos dizer corretamente em uma época (segundo as regras da gramática e da lógica) e o que é dito efetivamente" (FOUCAULT, 2010, p. 14). Nesse escopo, é importante compreender também em que consistem essas diferenças entre o enunciável e o visível, no que concerne à formação de leitores. Diante da concepção de língua(gem) que norteia o ensino da Língua Portuguesa, e partindo dessa práxis discursiva, é que cabe um olhar para as concepções de leitura presentes nos documentos do MEC.

A história da leitura tornou-se fértil campo de pesquisas, especialmente a partir da década de 1970, em decorrência da matriz historiográfica desenvolvida na França que ficou conhecida como "Nova História" e que despertou, nos estudiosos, interesse em ampliar objetos, abordagens e problematizações nas áreas do conhecimento. Dentre os objetos de predileção, situam-se as práticas de leitura e suas transformações no decorrer da história da humanidade. Essa matriz inovadora que direcionou a forma de pensar os objetos convergia para a história das práticas (BERTOLLI, 2017) ${ }^{6}$.

Após salientar a complexidade de tal estudo, "dificultada tanto pela raridade dos vestígios diretos quanto pela complexidade da interpretação dos indícios indiretos" (CHARTIER, 2011, p. 77), percebe-se como essas práticas estão relacionadas também à história dos suportes de veiculação dos textos, considerando, em suas muitas publicações, um trajeto que vai das tabuinhas com escrita cuneiforme (da Antiga Mesopotâmia) até a escrita digital, feita na tecla, na tela por touch screen (BERTOLLI, 2017) e cujas peculiaridades, contextos e sujeitos nos levam a constatar que,

com efeito, todo autor, todo escritor impõe uma ordem, uma postura, uma atitude de leitura. Que seja explicitamente afirmada pelo escritor ou produzida mecanicamente pela maquinaria do texto, inscrita na letra da obra como também nos dispositivos de sua impressão, o protocolo da leitura define quais devem ser a interpretação correta e

\footnotetext{
${ }^{6}$ Este breve percurso histórico da leitura - constituído pelos próximos três parágrafos - foi adaptado da Dissertação de Mestrado em Estudos Linguísticos de Sarah Suzane Bertolli Gonçalves (2017, p. 70).
} 
o uso adequado do texto, ao mesmo tempo em que esboça o leitor ideal (CHARTIER, 2011, p. 20).

Ao se debruçar sobre a leitura de livros (impressos), Chartier (2011) reflete/discorre sobre a perpetuação da memória, de escritos raros, preciosos e também sobre como, tanto nos tempos dos livros manuscritos quanto com o advento da imprensa, essa preocupação de preservação era uma inquietação dos autores (BERTOLLI, 2017). Convém lembrar que, “[n]o século XIX, os três grandes discursos sobre a leitura, o da escola, o da Igreja e o da biblioteca - que correspondem a três corpos profissionais [...], os padres, os professores, e os bibliotecários -, tinham conteúdos diferentes [...]" (CHARTIER, 1999, p. 113). Esses três discursos de autoridade se desarticulam, possivelmente porque os sujeitos, os espaços e suas representações se distanciaram dessas instituições enunciadoras, o que revela como "as práticas de leitura emanciparam-se frente às ordens e normas" (CHARTIER, 1999, p. 113).

Sabemos, entretanto, que nem sempre o sistema educacional disciplinador permite essa plena emancipação e, a depender do contexto político-social, as delimitações se tornam mais margeadas, aprisionando os sujeitos envoltos nessa conjuntura, também os leitores.

Em contrapartida, diante da teoria de Chartier, vemos que essa emancipação pode acontecer quando docentes e discentes rompem o imposto quanto aos temas, conteúdos e habilidades requeridos para determinada faixa etária e promovem projetos de leitura integrados à realidade social da comunidade escolar. Esse rompimento, por vezes, é necessário, já que "a compreensão do texto a ser alcançada por sua leitura crítica implica a percepção das relações entre o texto e o contexto" (FREIRE, 2015, p. 9).

Diante disso, considerar os gêneros digitais na sala de aula revela esse afinamento textocontexto, agregando os campos de atividade humana, ao não restringir as práticas ao trabalho com gêneros tipicamente escolares. Na história da leitura, percebemos que

[o] leitor da tela assemelha-se ao leitor da Antiguidade: o texto que ele lê corre diante
de seus olhos; é claro, ele não flui tal como o texto de um livro em rolo, que era preciso
desdobrar horizontalmente, já que agora ele corre verticalmente. De um lado, ele é
como o leitor medieval do livro impresso, que pode usar referências como a
paginação, o índice, o recorte do texto. Ele é simultaneamente esses dois leitores. Ao
mesmo tempo, é mais livre. O texto eletrônico lhe permite maior distância com relação
ao escrito. Nesse sentido, a tela aparece como ponto de chegada do movimento que
separou texto e corpo. O leitor do livro em forma de códex coloca-o diante de si sobre
uma mesa, vira suas páginas ou então o segura quanto o formato é menor e cabe nas
mãos. O texto eletrônico torna possível uma relação mais distanciada, não corporal
(CHARTIER, 1999, p. 16).

Constata-se, portanto, que inclusive as posturas de leitura se cambiaram nos tempos modernos das redes sociais digitais e das tecnologias da comunicação. Entretanto, a leitura mais voltada à contemplação ainda persiste, por tradição ou relação texto-corpo, como mais Revista Graphos, vol. 21, n 1, 2019 | UFPB/PPGL | ISSN 1516-1536 
legitimada pelo livro impresso (CHARTIER, 1999). A hipótese é que, nessa perda constatada na relação texto e corpo entre leitor e obra, o formato códex permitiria mais proximidade. Por outro lado, é certo que a mobilidade garantida pela rápida interação na internet encaminha práticas leitoras mais fluidas e dialógicas, sendo possível perceber (re)posicionamentos interpretativos em virtude dessa troca com outros sujeitos.

Ao abordar o tema da leitura, Eco (2002) discorre a respeito do jogo dialético existente entre autor e leitor. Contextualiza o papel do leitor, que, em contato com o texto, se põe a analisar o dito, mas também o não-dito. Esclarece que as inferências podem ser sugeridas pelos espaços vazios (entremeados em branco na página), e que podem inclusive figurar como estratégia discursiva do autor. Eco (2002) elucida ainda como se constitui o Leitor-Modelo, previsto pelo autor e cujos movimentos de escritura, no escopo do que ele nomeia de 'cooperação textual', direcionam a textos abertos ou mais fechados. Diante disso, vislumbra-se a possibilidade de um leitor como Proust foi com os horários dos trens, que ressignifica e opere de forma inusitada essa materialidade (ECO, 2002).

Ao pensarmos a didatização da leitura, via materiais e sequências escolares, à luz da explanação teórica de Eco (2002) e Chartier (1999), será que estamos formando leitores capazes de ler esses não-ditos? Crianças e jovens brasileiros, constituídos por práticas fechadas que partem de seleção de textos geralmente de natureza também fechada, são capazes de realizar uma leitura crítica e empreender estratégias de interpretação? E como fica a complexa questão do afinamento (bem desalinhado, por vezes) entre as práticas escolares estanques da tradição e esse viés de ensino que considera os gêneros da cultura digital?

Os resultados do Enem - Exame Nacional do Ensino Médio ${ }^{7}$, amplamente midiatizados pelos veículos impressos e virtuais, demonstram como há lacunas a serem preenchidas no ensino, sobretudo em relação à inferência, no reconhecer informações que estão implícitas. Eco (2002) lança alguns caminhos (dos quais precisamos partir para mudar essa realidade), que são introduzidos por uma máxima: o texto não pode ter uma margem unívoca. Esse autor aborda, inclusive, a necessidade de ultrapassar a função didática, para possibilitar o encontro com caminhos de leitura de propósitos mais estéticos-culturais, ou seja, voltados à formação de

\footnotetext{
7 O relatório inicial dos dados quantitativos do ENEM 2017 encontra-se disponível em: <http://portal.inep.gov.br/artigo/-/asset_publisher/B4AQV9zFY7Bv/content/inep-mec-divulgam-resultados-doenem-2017-e-anunciam-calendario-do-exame-em-2018/21206>. Acesso em 25 jul. 2018. No sítio no INEP, os demais resultados, de seleções anteriores, também foram veiculados. Esses dados demonstram como a escola básica brasileira precisa (toda a comunidade escolar e também as políticas educacionais e sociais) dar realce ao ensino da leitura e da compreensão do texto.
} 
leitores capazes de compreender textos literários e relacioná-los com contextos e outras leituras, o que "abre a iniciativa interpretativa" (2002, p. 37).

Entretanto, o que vislumbramos em alguns cenários escolares é justamente a voz docente ecoando como verdadeira na análise do texto, sem que haja troca de olhares e leituras. Também, é possível constatar como a função didática sobrepuja a estética, a começar com a escolha unívoca do texto solicitado pelo Enem para composição textual, que acaba ditando o conteúdo da disciplina Língua Portuguesa nos anos finais da escola básica. Nesse cenário contemporâneo e diante da perspectiva de ensino descrita na BNCC, é importante marcarmos quais as concepções discursivas, seus gêneros e os motivos pelos quais esse viés contribui para a formação crítica dos alunos.

\section{Concepções de discurso e de gênero discursivo na BNCC}

Bakhtin explora (2011) como a interação com o outro é indispensável à comunicação das pessoas e está expressa em diferentes manifestações linguísticas inseridas em campos de atividades humanas. Ao discutir os conceitos de língua, enunciado e gênero discursivo, o teórico russo enfatiza a inserção sócio-histórica dos gêneros, considerando não apenas essa construção espaço-temporal, como também suas modelações e atualizações.

Gêneros discursivos são considerados como tipos "relativamente estáveis de enunciados", cuja classificação se dá em virtude do tema, da forma composicional e do estilo da linguagem (BAKHTIN, 2011, p. 262). Cada esfera (ou campo) conhece os gêneros de sua especificidade, o que revela a heterogeneidade dos gêneros do discurso. Ele aprofunda essa explanação teórica ao abordar também, além do problema e da definição, o enunciado como unidade de comunicação discursiva, ao tratar da diferença entre essa unidade e as unidades da língua (palavras e orações).

Percebe-se que uma das bases epistemológicas do documento mais recente do MEC advém da teoria bakhtiniana, como se pode ver neste trecho: "o texto ganha centralidade na definição dos conteúdos, habilidades e objetivos, considerado a partir de seu pertencimento a um gênero discursivo que circula em diferentes esferas/campos sociais de atividade/comunicação/uso da linguagem." (BNCC, 2017, p. 65). Com a atualização espaçotemporal e a construção sócio-histórica das classificações dos textos, a BNCC possui esse viés.

Reconhece-se Bakhtin na parte de Linguagens no citado documento na própria estruturação, ao se organizar os quadros de conteúdos em campos de atividades, empregando a terminologia práticas sociais, que promovem uma visão mais ampla do conceito e dos usos dos 
textos em diversas esferas. Tal perspectiva busca não privilegiar certos tipos ou contextos de uso, como ecoam certas práticas tradicionais escolares, em que se escrevia uma redação ou se lia uma narrativa e um poema, com ênfase em questões gramaticais e não se proporcionava uma leitura mais profunda, que acionasse reflexão a respeito dos contextos de uso da língua, por exemplo.

Na linha de formação integral dos sujeitos (um dos pilares importantes da BNCC, conforme traz a introdução desse documento orientador curricular), há espaço para essa metodologia de ensino que perfaz a pluralidade textual e persegue o problema não somente em sua forma, mas também quanto à temática e ao estilo de linguagem. Diante da normativa, portanto, há vislumbre de uma práxis pedagógica para as aulas de Língua Portuguesa que não se restrinja à abordagem gramatical.

Perseguindo o que seria uma abordagem discursiva de ensino de língua, para pensar a respeito do tratamento didático da leitura na contemporaneidade nesse viés, convém analisar, com Foucault (2010), a conceituação de discurso:

o discurso não deve ser assumido como o conjunto das coisas que se diz, nem como
a maneira de dizê-las. Ele está outro tanto no não dito, ou no sinalizado por gestos,
atitudes, modos de ser, esquemas de comportamento, deslocamentos espaciais. O
discurso é o conjunto das significações coercivas e constrangedoras que perpassam
as relações sociais (FOUCAULT, 2010, p. 123).

Courtine (2013, p. 27) complementa que "o discurso deve ser compreendido a partir daquilo que Foucault denomina dispositivo, isto é, de um conjunto heterogêneo de instituições e de leis, de coisas e de ideias, de atos e de práticas, de palavras e de textos, de ditos e de não ditos". Veyne, por outro lado, evoca uma metáfora visual para descrever que os discursos "são os óculos através dos quais, em cada época, os homens perceberam toda coisa, pensaram e agiram" (2014, p. 46).

Nesse escopo, é importante problematizar a ordem do discurso do sistema educacional, tendo em vista a marcada e histórica dualidade estrutural da educação, com uma escola que mobiliza conhecimentos voltados à formação cultural, cognitiva, intelectual (direcionada à elite) e outra para trabalhos manuais (conduzida para os filhos das classes sociais mais baixas, que servirão de mão de obra no futuro - ou mesmo no presente!). Vê-se que a educação, ainda que seja, de direito, "o instrumento graças ao qual todo indivíduo, em uma sociedade como a nossa, pode ter acesso a qualquer tipo de discurso, é bem sabido que segue [...] as linhas que estão marcadas pela distância, pelas oposições e lutas sociais" (FOUCAULT, 2006, p. 41). É importante considerarmos esse viés em nossa discussão, já que "é tão impossível negar a 
natureza política do processo educativo quanto negar o caráter educativo do ato político" (FREIRE, 2015, p. 15).

Tal reflexão nos remonta à história da educação brasileira, marcada por lutas intensas, sobretudo nas décadas de 1980 e 1990, por leis que pretendiam promover uma igualdade entre as pessoas. Sabemos que a Lei de Diretrizes e Bases da Educação (LDB, 1996) e o movimento de parametrização não "salvaram" o nosso país, mas inauguraram, no plano legal, uma análise mais apurada do que seria uma escola unitária (pensando no conceito elaborado por $\mathrm{Gramsci}^{8}$ ). A BNCC também trouxe debates para o meio educacional, sobretudo pelas idas e vindas nas reformulações do documento. Dentre as polêmicas, destacamos: parte do ensino médio ser ofertado à distância, ensino médio técnico integrado com ênfase em disciplinas focadas no mercado de trabalho, retirada de disciplinas, apagamento da educação literária no ensino fundamental etc. Alguns desses tópicos foram modelados ou completamente alterados no percurso de constituição do documento, ou seja, de 2015 a 2018, ano de implementação e debate da BNCC.

Sabe-se que o discurso pedagógico também segue esse ordenamento, esse controle, por isso tal fixação de papéis, de sujeitos destinados a ocupar certos espaços e censurados a adentrar em outros. Entretanto, mesmo no sistema imposto de coerções e objetivos cada vez mais marcados, com determinação de que sujeito se deseja formar (aquele moldado aos interesses do mercado, do trabalho), vislumbramos significativos avanços nas normativas do MEC, de vinte anos para cá, culminando com a publicação da BNCC, que, além do viés discursivo para o ensino de Língua Portuguesa, salienta a importância dos gêneros digitais e multiletramentos desde os anos iniciais da escolarização.

\section{Discussão e análise de normativas do MEC: PCN e BNCC}

A BNCC é publicada e implementada em meio a problematizações várias pelo país, com intenções de debater diversos pontos da normativa: da estruturação à seleção dos conteúdos presentes. Esse movimento de reflexões e discussões alude a outro momento histórico de inauguração de documento educacional em nosso país: o advento dos PCN. Vários foram os pesquisadores que teceram análises críticas e muitos foram os espaços de diálogo para compreensão desse documento no fim da década de 90 (BRAIT, 2000; MARCUSCHI, 2008).

\footnotetext{
${ }^{8}$ A Escola Unitária propunha um modelo integral de ensino, com participação interativa de docente e discentes na pesquisa, na empiria, mas também na aquisição de saberes filosóficos, sociais, culturais, que mobilizem emancipação do sujeito. Tal conceito é explorado no seguinte artigo: http://www.opet.com.br/faculdade/revistapedagogia/pdf/n13/artigo6.pdf.
} 
Tais debates foram oportunos para que os Parâmetros passassem, à semelhança do que aconteceu com a BNCC, por idas e vindas, por modelações e alterações. Também como similaridade entre esses documentos, há a questão da não creditação de teorias, ou seja, ainda que teorias de base textual e discursiva, no âmbito dos estudos linguísticos, sejam reconhecidas nas linhas dos PCN - como acontece com a abordagem de gênero discursivo e de tipologia textual -, não consta referenciação específica às pesquisas (BRAIT, 2000).

Quanto ao recorte temático deste estudo, ou seja, às concepções e práticas de leitura sugeridas nessas normativas, podem ser percebidas da seguinte maneira:

Quadro 1 - Comparação PCN e BNCC sobre conceitos e práticas de leitura

\begin{tabular}{|c|c|c|}
\hline DOCUMENTOS MEC & PCN, 1997 & BNCC, 2017 \\
\hline Conceito de leitura & $\begin{array}{l}\text { "A leitura é um processo no qual } \\
\text { o leitor realiza um trabalho ativo } \\
\text { de construção do significado do } \\
\text { texto, a partir dos seus objetivos, } \\
\text { do seu conhecimento sobre o } \\
\text { assunto, sobre o autor, de tudo o } \\
\text { que sabe sobre a língua: } \\
\text { características do gênero, do } \\
\text { portador, do sistema de escrita, } \\
\text { etc. Não se trata simplesmente } \\
\text { de extrair informação da escrita, } \\
\text { decodificando-a letra por letra, } \\
\text { palavra por palavra. Trata-se de } \\
\text { uma atividade que implica, } \\
\text { necessariamente, compreensão } \\
\text { na qual os sentidos começam a } \\
\text { ser constituídos antes da leitura } \\
\text { propriamente dita". (p. 41) }\end{array}$ & $\begin{array}{l}\text { "O Eixo Leitura compreende as } \\
\text { práticas de linguagem que } \\
\text { decorrem da interação ativa do } \\
\text { leitor/ouvinte/espectador com os } \\
\text { textos escritos, orais e } \\
\text { multissemióticos e de sua } \\
\text { interpretação, sendo exemplos as } \\
\text { leituras para: fruição estética de } \\
\text { textos e obras literárias; pesquisa } \\
\text { e embasamento de trabalhos } \\
\text { escolares e acadêmicos; } \\
\text { realização de procedimentos; } \\
\text { conhecimento, discussão e } \\
\text { debate sobre temas sociais } \\
\text { relevantes; sustentar a } \\
\text { reivindicação de algo no } \\
\text { contexto de atuação da vida } \\
\text { pública; ter mais conhecimento } \\
\text { que permita o desenvolvimento } \\
\text { de projetos pessoais, dentre } \\
\text { outras possibilidades." (p. 69) }\end{array}$ \\
\hline Práticas de leitura & $\begin{array}{l}\text { "Eis a primeira e talvez a mais } \\
\text { importante estratégia didática } \\
\text { para a prática da leitura: o } \\
\text { trabalho com a diversidade } \\
\text { textual. Sem ela pode-se até } \\
\text { ensinar a ler, mas certamente } \\
\text { não se formarão leitores } \\
\text { competentes" (p. 55). }\end{array}$ & $\begin{array}{l}\text { "Os conhecimentos sobre os } \\
\text { gêneros, sobre os textos, sobre a } \\
\text { língua, sobre a norma-padrão, } \\
\text { sobre as diferentes linguagens } \\
\text { (semioses) devem ser } \\
\text { mobilizados em favor do } \\
\text { desenvolvimento das } \\
\text { capacidades de leitura, produção } \\
\text { e tratamento das linguagens, que, } \\
\text { por sua vez, devem estar a } \\
\text { serviço da ampliação das } \\
\text { possibilidades de participação } \\
\text { em práticas de diferentes esferas/ } \\
\text { campos de atividades humanas" } \\
\text { (p. 65) }\end{array}$ \\
\hline
\end{tabular}

Fonte: Elaborado pelos pesquisadores deste trabalho, partindo dos referidos documentos normativos do MEC. 
Em analogia, é possível perceber, entre esses documentos, afinamentos quanto ao 'como' deve ser ensinada a leitura em sala de aula, partindo da diversidade conceitual e das práticas escolares. Ainda, é notável como há ampliação teórica de aspectos textuais e discursivos, que na BNCC emergem de modo mais pontual, sendo possível reconhecer os estudos bakhtinianos como base para essa normativa, ainda que o devido crédito ou referência não apareça no documento, mas sendo evidente o uso de termos explanados à exaustão pelo filósofo, como 'campo de atividade humana' e a própria noção de 'gênero' nesse viés de texto e discurso. Esse avanço já estava predito (ou melhor, era esperado), já que se entende que na sociedade contemporânea “(...) exigem-se níveis de leitura e de escrita diferentes e muito superiores aos que satisfizeram as demandas sociais até bem pouco tempo atrás - e tudo indica que essa exigência tende a ser crescente" (BRASIL, 1997, p. 25).

Vinte anos depois, surge a BNCC, que envolve a dinâmica dos gêneros digitais e sugere que, no contexto escolar, sejam considerados os multiletramentos para garantir uma “participação mais efetiva e crítica nas práticas contemporâneas de linguagem” (2017, p. 68). Obviamente, essa ainda não é a tônica de alguns contextos escolares, pois é preciso considerar que há outras regras de funcionamento de muitas aulas de português, tendo em vista fatores econômicos, políticos e sociais, cuja conjuntura impossibilita, em muitos momentos, o acesso às tecnologias da comunicação e da informação (TICs) para todos os estudantes brasileiros.

Emergem na mídia notícias que informam dados de pesquisa sobre isso; uma delas, veiculada pelo sítio de notícias G1 (7 fev. 2016), revela as problemáticas do ensino público quanto às TICs, considerando que apenas $43 \%$ das escolas brasileiras, naquela época, tinham internet banda larga ${ }^{9}$.

A respeito dos itinerários do ato de ler, como estamos nomeando aqui os caminhos possíveis de leitura que devem ser considerados para compreensão de um texto, a BNCC (2017, p. 71 e 72) elenca: reflexão a respeito das condições de produção/recepção de diferentes mídias e esferas/campos de atividade humana, dialogia, reconstrução da textualidade, reflexão crítica sobre a temática tratada e validade das informações, compreensão dos efeitos de sentido provocados pelos usos de recursos linguísticos e multissemióticos em textos pertencentes a gêneros diversos, práticas de leitura etc. Percebe-se como os mencionados termos pertencem a teorias do texto e do discurso, ainda que não estejam devidamente creditadas aos respectivos pesquisadores. Não apenas os termos evidenciam um caminho crítico para a leitura, para além

\footnotetext{
9 Notícia disponível em: <http://g1.globo.com/educacao/noticia/2016/01/43-das-escolas-publicas-tem-bandalarga-contra-80-das-privadas.html>. Acesso em: 02 ago. 2018.
} 
da decodificação, mas também o desdobramento das expectativas de aprendizagem para cada ano revela a pretensão de formar leitores mais ativos e capazes de usar a linguagem como prática social nesse nível de complexidade.

Conforme explica Bourdieu (1977, p. 168-169), "é necessária a constituição de dispositivos de rompimento ou interrupção do fluxo rotineiro das ações para que os mecanismos de sustentação sejam contemplados pelos sujeitos." Assim, o discurso pedagógico da leitura passou por rompimentos que foram visíveis na transformação das práticas. Tal constatação pode ser observada no âmbito da sala de aula e no avanço do tratamento didático da língua presente nas citadas normativas. Foucault (2010, p. 22) explica que "uma política progressista é uma política que reconhece as condições históricas e as regras específicas de uma prática." Portanto, o que emerge como visibilidade no tratamento didático da leitura é uma transformação nas políticas educacionais, parametrizadas por documentos do MEC, como os PCN - que possuem viés discursivo, valorizam a leitura e a importância da autonomia do aluno.

Esse salto (no plano normativo) dessas práticas de leitura data o advento dos PCN (1997), sendo importante recordar como se dava a aprendizagem da leitura e também da escrita em décadas anteriores. Nessa alusão, as cartilhas alfabetizadoras nos dão um vislumbre de como se manifestava o ensino da linguagem. É importante compreender que certas práticas escolares tradicionais, em alguns contextos, ainda vigoram, isso comprovado pela simples conferência de listas de materiais escolares, ou um passeio pelas livrarias de alguma cidade, para perceber como ainda há venda e procura por esses instrumentos de ensino da leitura e da escrita ${ }^{10}$. Mesmo entre os materiais didáticos ditos atualizados, há resquícios de uma tradição escolar que toma(va) o ensino da leitura como decodificação de unidades menores da língua.

Nesse sentido, contextualiza-se que as práticas sociais de uso da leitura e da escrita, no avanço histórico do ensino, começaram a ser entendidas como fenômeno sociolinguístico envolto em práticas ideológicas de relações de poder, significados e práticas socioculturais específicas, partindo das pesquisas desenvolvidas pelos Novos Estudos do Letramento (STREET, 2014).

Street (2014) reconhece que as práticas de uso da linguagem estão sempre inseridas em significados culturais e posturas ideológicas a respeito da própria conceituação de 'letramento' e nas relações de poder a ele associadas. Assim, acreditamos que a lógica capitalista imperante

\footnotetext{
${ }^{10}$ Há muitos estudos a respeito da história das cartilhas alfabetizadoras no ensino da leitura e da escrita no Brasil. A tese de doutorado de Vieira (UESB, 2017) conclui que, no contexto escolar, "o que vemos é que cada nova cartilha traz sempre ecos de uma tradição que ficou marcada na memória de quem um dia utilizou-se desse referencial na sua construção de leitor-autor." (p. 188). Disponível em: <http://www2.uesb.br/ppg/ppgmls/wpcontent/uploads/2017/09/Tese-Zeneide-Paiva-Pereira-Vieira.pdf>. Acesso em: 25 jul. 2018.
}

Revista Graphos, vol. 21, n 1, 2019 | UFPB/PPGL | ISSN 1516-1536 
na política educacional brasileira, ao manter a dualidade estrutural da educação e ao marcar, nitidamente, a vinculação entre educação e trabalho, certamente manifesta esse afinamento com a cultura digital no ensino básico com essa pretensão de formar trabalhadores mais capacitados a manusear essas ferramentas, tendo em vista essa necessidade de uso dos instrumentos tecnológicos na contemporaneidade.

Convém salientar que, para Street (2014), as implicações dos Novos Estudos do Letramento para as atividades pedagógicas se situam na necessidade, solicitada também por estes tempos. Assim, a escola precisa extrapolar o ensino de aspectos técnicos das funções da linguagem, ensinando os alunos na compreensão da natureza social e ideologicamente construída das formas específicas que habitamos e que usamos em determinados momentos.

Partindo de uma contextualização da origem histórica do termo 'letramento' até alcançar a descrição das finalidades e práticas desse tipo de pedagogia na contemporaneidade, convém compreendermos que a perspectiva de 'multiletramentos' se distingue porque esse "multi" aponta para "a multiplicidade cultural das populações e a multiplicidade semiótica de constituição dos textos por meio das quais ela se informa e comunica." (ROJO, 2012, p. 13). Considerando a esfera escolar para elencar possibilidades de inserção dessa multiplicidade, Rojo (2012) explica que o hipertexto e os multiletramentos requerem uma nova ética e novas estéticas, numa abordagem crítica e interativa.

Quanto às multissemioses, a pesquisadora relaciona esse conceito às múltiplas linguagens do contexto contemporâneo e do sujeito atual, nativo digital, imerso em tais tecnologias. A explanação é conduzida para uma reflexão a respeito de como funcionam os multiletramentos, situados num escopo interativo e dialogal, bem como propõe "como" fazer uma pedagogia dos multiletramentos, parte na qual a autora problematiza o cenário educacional brasileiro, diante das desigualdades e desvalorização dos professores; e também elabora como a noção de multiletramentos está enquadrada em letramentos críticos, que "buscam interpretar contextos sociais e culturais de circulação e produção desses designs e enunciados" (ROJO, 2012, p. 30).

Nitidamente, na leitura da BNCC (2017), percebemos essa perspectiva de ensino, manifesta nos termos e nos desdobramentos didáticos da normativa, ao integrar os campos escolares e cotidianos, alinhados ao uso de instrumentos da cultura digital, demonstrando como promover uma prática situada que remete a um "projeto didático de imersão em práticas que fazem parte da cultura do alunado" (ROJO, 2012, p. 30), ainda que tenhamos um percurso a trilhar quanto a inserir as TICs na realidade escolar do nosso País. 
Ao concluir seu trabalho abordando a vigência das práticas tradicionais de ensino em alguns contextos, Rojo argumenta que "[...] felizmente, no caso do Brasil, não nos vemos constrangidos a tanto, talvez por termos começado há mais tempo (com a proposta paulofreiriana, por exemplo)" (2012, p. 31). A defesa de Rojo (2012) é a culminância de um contraponto de perspectivas pedagógicas que ela descreve. Apresenta, de um lado, um ensinoaprendizagem que considera: 1. prática situada, 2. instrução aberta, 3. enquadramento crítico, 4. prática transformadora. Contrapõe tal percurso a um movimento reacionário que a autora descreve como presente nos EUA e na Europa, que retoma as propostas tradicionais de: 1. experimentar, 2. conceitualizar, 3. analisar e 4. aplicar. O contraponto entre esses dois caminhos metodológicos se encontra especialmente na consideração de que, partindo de uma prática situada de imersão em situações de aprendizagem abertas às culturas e às vivências dos alunos, se compreende que o texto não possui uma margem unívoca, acionando criticamente a compreensão leitora dos sujeitos, de modo que sejam capazes de questionar, fazer relações, analisar as condições de produção e recepção dos discursos. Tais relações evocam análise de contextos sociais numa abordam plural, transdisciplinar - ou seja, um trajeto diferente do proposto pela escola tradicional, no qual o conteúdo geralmente tem um fim em si mesmo.

Ao analisar a parte final do artigo de Rojo (2012) e também o cenário educacional vigente no Brasil, tendo em vista a linha teórico-metodológica de manuais didáticos e das práticas escolares, parece que a escola contemporânea não se desapega ainda da linha tradicional e isso se reflete nos exames nacionais de grande escala, que servem para mensurar/avaliar (também) a Educação Básica - cujo diagnóstico pouco ou raramente impulsiona mudança, principalmente agora nestes tempos de cortes na educação, congelamento salarial dos servidores dessa área, desemprego de educadores, sucateamento da pesquisa e do ensino (devido à escassez de investimentos) etc. ${ }^{11}$

Ao problematizar tal defesa da autora, também pensamos se esse "felizmente..." reflete mesmo a realidade do Brasil atual, já que parece bem estranho pensarmos que nossas escolas possuem uma linha freiriana de ensino, diante de tantas complexidades, que envolvem também o cerceamento daqueles que ousam resistir. Prova disso também é a euforia criada no Ensino Médio e nos cursinhos superlotados em todo o Brasil que se voltam não a uma formação humana de prática transformadora do sujeito e da pedagogia, mas tem enfoque unilateral: o ENEM e seu texto dissertativo-argumentativo. Daí emergem as fórmulas, os esquemas, as

11 Esse cenário atual do campo educacional pode ser atestado por notícias como esta: <https://g1.globo.com/educacao/noticia/veja-o-impacto-do-corte-de-verbas-em-universidades-e-institutosfederais-de-14-estados.ghtml>. Acesso em 01 ago. 2018.

Revista Graphos, vol. 21, n² 1, 2019 | UFPB/PPGL | ISSN 1516-1536 
decorebas e, quando muito, uma linha de ensino (infelizmente) tradicional, no viés posto por Rojo (experimentar, conceitualizar, analisar e aplicar), bem distante dos multiletramentos.

\section{Prática de leitura na cultura digital: um exemplo textual ${ }^{12}$}

Partindo da concepção de leitura como compreensão e estando essa prática imersa, sobretudo na contemporaneidade digital, na diversidade - de olhares, posturas ideológicas e sociais, caminhos e gêneros discursivos -, compartilhamos um exemplo de prática de leitura mobilizada em meio digital, a saber: uma postagem de blog, cujos comentários também foram analisados, numa análise intertextual do discurso, tendo em vista esse "nó em rede" (FOUCAULT, 2014, p. 28) de remissões a outros textos e obras, já que

a obra, como no diálogo, está disposta para a resposta do outro (dos outros) para a sua
ativa compreensão responsiva, que pode assumir diferentes formas: influência
educativa sobre os leitores, sobre suas convicçôes, respostas críticas, influência sobre
seguidores e continuadores, ela determina as posições responsivas dos outros nas
complexas condições de comunicação discursiva de um dado campo de cultura
(BAKHTIN, 2011, p. 279).

Diante da teoria, considera-se que essa compreensão responsiva, no contexto da interlocução, vigora não apenas em gêneros primários, mas também nos secundários, mais complexos (BAKHTIN, 2011), alcançando também a teia da cultura digital.

Antes de compartilharmos aqui a citada postagem, elucidamos que a postagem de blog, sendo um gênero da cultura digital, tende a "uma certa informalidade, menor monitoração e cobrança pela fluidez do meio e pela rapidez do tempo" (MARCUSCHI, 2008, p. 202). Tais características já geram distanciamento na abordagem metodológica em sala de aula, para o ensino de um texto com essas especificidades ao contrapormos com o enfoque das aulas de português de parâmetros e concepções mais tradicionais, cuja base gramatical servia para avaliação de textos mais formais e, por vezes, alheios à realidade do aluno da escola básica. Vale lembrar que nos desdobramentos do eixo da leitura a BNCC também evoca a 'norma padrão'.

Em práticas de leitura da cultura digital, percebemos como há interação e (re)posicionamentos interpretativos dos textos. Eis um exemplo de uma postagem de um blog, gênero constituído pela evolução sócio-histórica das materialidades textuais e que advém dos

\footnotetext{
${ }^{12}$ Esta seção não se propõe a aprofundar conceitos mencionados no texto mobilizado como exemplo, mas apenas busca ilustrar como se constitui e emerge uma prática de leitura em meio digital, que possua canal de interação entre autor-leitores.
} 
diários e relatos pessoais, mas contendo finalidades outras agregadas, tendo em vista maior visibilidade pela ampliação do contexto de recepção.

A postagem figura no blog "Notas sobre uma escolha", cujo intuito central da autora é compartilhar com seus leitores o estilo de vida avesso ao sistema capitalista, busca perseguida com a mudança para uma comunidade no campo e luta contra o trabalho formal remunerado tal qual conhecemos. O blog foi inaugurado em julho de 2013, diante dessa experiência pela qual passa a autora (Malu Franco) e sua família. Na home page, consta a justificativa da autora, para sua escrita:

aqui estão notas sobre nossa última grande escolha: romper uma certa zona de conforto e nos jogar na aventura de uma vida mais sustentável e bonita. Por nós, pelos filhos que temos, pelo tempo rei que voa, pelo respeito à natureza, pelo amor que pulsa em nosso corpo família (FRANCO, s/n).

Abaixo, segue o print da página de uma postagem, de 19 de maio de 2015, que aborda o tema da escola.

Figura 1 - postagem do blog "Notas sobre uma escolha"

\begin{tabular}{|c|c|}
\hline $\begin{array}{l}\text { wiosizurs I } \\
\text { A escola }\end{array}$ & Manu Melo France $\Delta$ ev \\
\hline 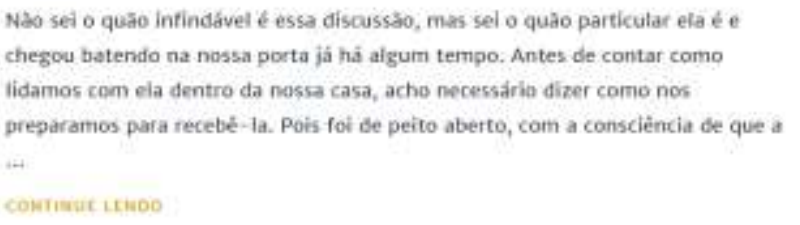 & \\
\hline 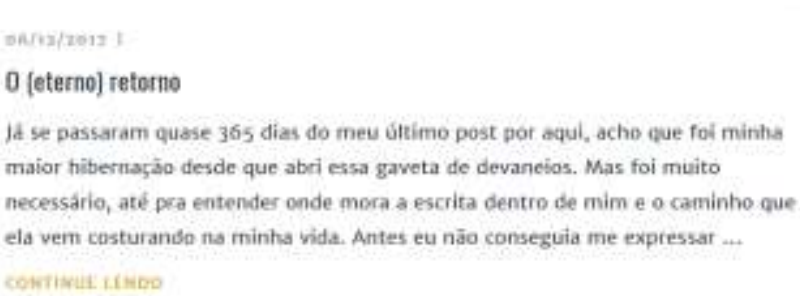 & $\begin{array}{l}\text { Aquariana filha de Oxum, mäe } \\
\text { do Tomé e da Nina, fugiu da } \\
\text { cimza pra se jogar na boiha } \\
\text { werde, Usa esta gaveca de } \\
\text { devaneios como divs pra } \\
\text { compartihar e nào pirar, Entre } \\
\text { se perder e se encontrar, é } \\
\text { cavalo arredio com patas de } \\
\text { fogo que corre pra imensidăo } \\
\text { do mar. }\end{array}$ \\
\hline
\end{tabular}

Fonte: https://notasobreumaescolha.wordpress.com/2015/05/19/a-escola/

Numa construção textual que se afina com o contexto em que ela está inserida, a autora defende que: "antes de pensarmos como a sociedade pensa, como nossos pais pensaram, como o sistema impõe, como nós [...] vivemos a escola, como seria 'certo ou errado', pensamos nas reais necessidades das crianças." (FRANCO, 2015, s/n). Nota-se que será elaborado mais que um relato, mas um texto revestido de posicionamentos, tendo em vista que a "característica 
interativa fundante da própria concepção de mídia digital permitiu que, cada vez mais, a usássemos mais do que para mera interação" (ROJO, 2012, p. 24).

Malu compartilha como decidiu, junto com seu marido, promover uma educação alternativa, na contramão da escolarização do sistema, principalmente porque não deseja expor as crianças a conceitos e valores com os quais não concorda. Compartilha como, certa feita, seu filho teve contato com um garoto "que frequenta uma escola, assiste televisão, usa o mesmo tênis daquele super-herói que todo mundo tem que ter, recebeu uma educação 'dentro do sistema'" (FRANCO, 2015, s/n) simula brincar com uma arma e como ela desaprova esse tipo de comportamento. Expõe como a escola nunca potencializou suas habilidades, ao contrário; e como ela almeja ofertar um ambiente de educação mais respeitoso e lúdico às crianças, concluindo que:

Essa é mais uma nota sobre mais uma escolha, estamos escolhendo educar crianças transformadoras, respeitando todo o seu potencial como seres de luz que são. E isso, (in) felizmente, não conseguimos sentir que poderia acontecer dentro das quatro paredes de uma sala de aula, nossos filhos pedem mais verdade e liberdade para ser por inteiro (FRANCO, 2015, s/n).

É possível perceber, no discurso da autora, um embate com as práticas tradicionais escolares, cujo enfoque puramente no cognitivo e a ausência de interação torna(vam) o ambiente escolar um lugar desvinculado da vida cotidiana (FREIRE, 2015). Estando inscrito em meio digital e trazendo a carga de sua inserção sócio-histórica, cujo tempo propicia a liberdade de expressão desse ponto de vista a respeito da instituição escola, esse texto recebeu 38 comentários $^{13}$, que poderiam ser agrupados em: a) concordantes; b) discordantes; c) silenciados. Essa organização criada aqui é meramente para demonstrar o motivo dos três exemplos selecionados, um de cada classificação, sendo que, no total, temos apenas cinco textos que demonstraram discordância da postagem de Franco sobre a escola, e um foi silenciado ou, pelo menos, fez essa menção à nulidade do comentário.

\footnotetext{
${ }^{13}$ Todos os comentários podem ser localizados no fim da postagem "A escola" do referido blog, texto disponível em: https://notasobreumaescolha.wordpress.com/2015/05/19/a-escola/. Acesso em: 31 jul. 2018.
} 
Figura 2 - comentários do blog "Notas sobre uma escolha"

a) comentário concordante

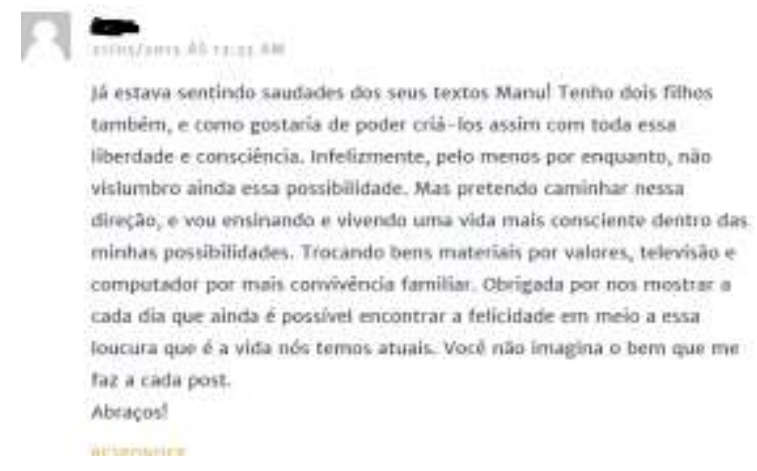

b) comentário discordante

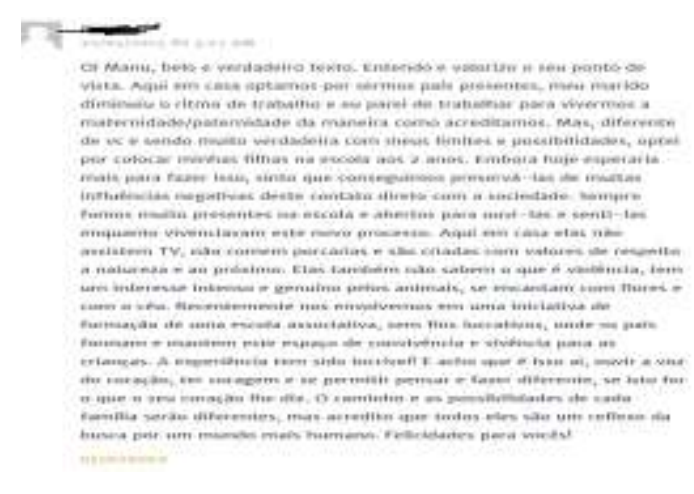

c) comentário silenciado

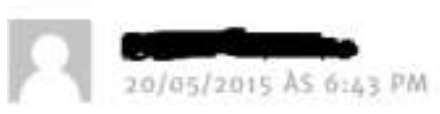

Porque meu comentário foi excluido?

\section{AESPONDEA}

Em geral, os comentários que estamos nomeando aqui como "concordantes" (dentre os quais compartilhamos, neste trabalho, somente um exemplo) manifestam, com adjetivações, a valorização do ponto de vista da autora a respeito de um ensino mais livre, em meio à natureza e fora do sistema escolar reconhecido. A maioria dos comentários é mais breve. Numa atividade responsiva que evoca a compreensão, lemos mobilizado um arsenal de experiências construídas sócio-historicamente e que enunciam o sujeito-leitor-autor que discorre sua opinião (BAKHTIN, 2011; MARCURSCHI, 2008).

Esse sujeito alude ao texto em interação, com marcações explícitas e que delimitam a argumentação. Percebemos esse tópico quando, no comentário discordante, compartilha sua experiência pessoal de ter uma filha que vai à escola, ou seja, que está inserida num sistema 
educacional que é criticado por Franco (2015) e, mesmo assim, não assiste TV ou come "porcarias", numa clara relação ao perfil tecido pela autora do texto "A Escola" a respeito do garoto escolarizado de meio urbano que, ao brincar com seu filho, se mostra uma "má influência" para as crianças da comunidade.

Quanto ao comentário silenciado (que foi supostamente excluído), percebemos que o discurso pode ser modelado, construído, numa teia interlocutiva, tendo em vista o poder que o autor de um suporte digital como o blog possui de manter ou suprimir o que bem desejar, de modo a também ampliar a compreensão de seu texto via comentários que passam pelo seu filtro. Essa palavra silenciada (FOUCAULT, 2006) revela propósito de limitação de itinerários possíveis de leitura. Ao mesmo tempo que manter o comentário "c" pode demonstrar esse poder para exclusão, numa prática que pode ser interpretada como de alerta aos demais sujeitosleitores do blog. Nota-se, assim, que, mesmo em meio a uma voz avessa ao sistema capitalista educacional de 'vigiar e punir', o discurso autoritário pode emergir.

\section{Considerações Finais}

Constatamos, neste trabalho, que entre os PCN e a BNCC houve avanço em relação ao tratamento didático de gêneros digitais e práticas de leitura, pelo menos quanto ao que está sugerido nas normativas do MEC (quanto à práxis pedagógica e à realidade escolar: é outra história). Sabemos que a escola básica brasileira ainda tem uma trajetória para alcançar, de modo efetivo e pleno, práticas de leitura que partam dos multiletramentos, e promovam o ato de ler como plural, direcionado à compreensão textual e numa abordagem discursiva. Essa dissonância entre a teoria e a prática acontece em virtude de fatores vários, alguns de ordem política e econômica, outros pelos arraigados modos de ensino, oriundos por vezes de práticas escolares tradicionais que precedem o movimento de parametrização e, por conseguinte, fomentam o ensino de Língua Portuguesa encarnado especificamente na gramática (MARCUSCHI, 2008).

Percebemos que a BNCC abarca conceituações e práticas mais amplas e plurais de leitura na escola, ainda que haja objetivos voltados aos interesses de mercado nesse documento, fato que emerge até mesmo nas propagandas do governo vigente e no papel do Ensino Médio nessa conjuntura político-social na qual estamos inseridos. A Base também integra campos de atividade humana, ao considerar os gêneros digitais na sala de aula, não restringindo o ensino de gêneros tipicamente escolares, tendo em vista que a escola forma pessoas para usarem a linguagem em diversas esferas sociais, inclusive no campo digital, como atestamos com o 
exemplo indicado no qual os sujeitos-leitores de um blog se posicionam quanto ao tema levantado, num jogo que revela concepções de ensino e de leitura.

Discordando de Rojo (2012) sobre a defesa de já termos uma abordagem freiriana na escola, compreendemos, entretanto, que, mesmo diante da heterogeneidade estrutural que o sistema educacional impõe, a BNCC encaminha para a escola possibilidades de promover a leitura da palavra-mundo. Mesmo que não tenhamos ainda a consolidação do modo de ensinar de Paulo Freire no chão da escola, podemos estar no caminho - ou melhor, compreender que a contemporaneidade digital tendo viabilizado a emergência mais intensa do diálogo com o outro, sem distâncias geográficas que impeçam essa interação, ela trouxe também - como itinerários - leitores e leituras mais fluidas e ativas; afinal, "o Brasil foi 'inventado' de cima para baixo, autoritariamente. Precisamos reinventá-lo em outros termos" (FREIRE, 2015, p. 21).

\section{Referências}

BAKHTIN, M. Os Gêneros Discursivos. In: Bakthin, M. Estética da Criação Verbal. São Paulo: Martins Fontes, 2011. 1979.

M. \& Voloshinov, V. N. Marxismo e filosofia da linguagem. São Paulo: Hucitec,

BERTOLLI, Sarah Suzane. O espaço da fruição literária na constituição do discurso pedagógico da leitura. Dissertação (Mestrado em Letras e Linguística). Programa de Pósgraduação em Letras e Linguística. Universidade Federal de Goiás. Goiânia, 2017. Disponível em: <https://repositorio.bc.ufg.br/tede/bitstream/tede/6907/5/Disserta\%C3\%A7\%C3\%A3o\%20$\% 20$ Sarah\%20Suzane\%20Am\%C3\%A2ncio\%20Bertolli\%20Ven\%C3\%A2ncio\%20Gon\%C3\%A7alv es\%20-\%202017.pdf>.

BOURDIEU, Pierre. Outline of a theory of practice. Cambridge e Melbourne: Cambridge University Press, 1977.

BRAIT, Beth. PCNs, gêneros e ensino de língua: faces discursivas da textualidade. In: ROJO, Roxane (org). A prática de linguagem em sala de aula: praticando os PCNs. São Paulo: EDUC, Campinas: Mercado das Letras, 2000. (Coleção As faces da Linguística Aplicada).

BRASIL. Ministério da Educação e da Cultura. Parâmetros Curriculares Nacionais: língua portuguesa. MEC/SEF, 1997.

. Ministério da Educação. Base Nacional Comum Curricular. Brasília: MEC, 2017. Disponível em: <http://basenacionalcomum.mec.gov.br/a-base>. Acesso em: 02 ago. 2018.

CHARTIER, Roger. Práticas de Leitura. Trad. Cristiane Nascimento. $5^{\mathrm{a}}$ ed. São Paulo, Estação Liberdade, 2011.

A aventura do livro: do leitor ao navegador. Tradução: Reginaldo Carmello Côrrea de Moraes. São Paulo: Editora UNESP, 1999. 
A história cultural: entre práticas e representações. Rio de Janeiro: DIFEL, 1988

CORSI, Solange. Formação literária em uma escola de tempo integral: novos modos de relação entre o jovem e os livros? (Tese. Doutorado - Estudos Linguísticos). Programa de Pós-graduação em Letras e Linguística, Universidade Federal de Goiás, Goiás, 2017. Disponível em: <https://repositorio.bc.ufg.br/tede/bitstream/tede/6978/5/Tese\%20$\% 20$ Solange\%20da\%20Silva\%20Corsi\%20-\%202017.pdf>. Acesso em>04 jul. 2018.

COURTINE, Jean-Jacques. Decifrar o corpo: pensar com Foucault. Petrópolis (RJ): Vozes, 2013.

DE CERTEAU, M. A invenção do cotidiano. Artes do fazer. Petrópolis (R.J): Vozes, 1994.

ECO, U. O leitor-modelo. In: Lector in fabula: a cooperação interpretativa nos textos narrativos. São Paulo: Perspectiva, 2002, p. 35-49.

FOUCAULT, M. A ordem do discurso. São Paulo: Loyola, 2006, p. 5 -60.

Resposta a uma questão. In: Ditos e Escritos IV: repensar a política. Rio de Janeiro: Forense Universitária, 2010.

A Arqueologia do saber. 8ed. Rio de Janeiro: Forense Universitária, 2014.

FRANCO, Malu Melo. A escola, 2015 In: Notas sobre uma escolha (blog). Disponível em: <https://notasobreumaescolha.wordpress.com/2015/05/19/a-escola/>. Acesso em: 01 ago 2018.

FREIRE, Paulo. A importância do ato de ler. 51 a edição. São Paulo: Cortez, 2015.

FRIGOTTO, Gaudêncio. A produtividade da escola improdutiva: um (re) exame das relações entre educação e estrutura econômico-social capitalista. São Paulo: Cortez, 1989.

GARCIA, Júlio Cézar. O ensino médio integrado no Instituto Federal Goiano: a percepção de professores sobre os desafios e possibilidades para a consolidação da formação humana integral. Tese (Doutorado em Educação). Pontifícia Universidade Católica de Goiás. Goiânia, 2017. Disponível em:

<http://tede2.pucgoias.edu.br:8080/bitstream/tede/3849/2/J\%C3\%9ALIO\%20C\%C3\%89ZAR $\%$ 20GARCIA.pdf?>.

KUENZER, Acácia Zeneida. Pedagogia da fábrica. 8. Ed. São Paulo, SP: Cortez, 2007.

MARCUSCHI. Luiz Antônio. Produção textual, análise de gêneros e compreensão. São Paulo: Parábola, 2008.

NOGUEIRA, Poliana Vieira. Do autor ao leitor: os processos que marcam o encontro das crianças e jovens com o livro. (Tese. Doutorado - Estudos Literários). Programa de Pósgraduação em Letras e Linguística, Universidade Federal de Goiás, Goiás, 2017. Disponível em: <https://repositorio.bc.ufg.br/tede/bitstream/tede/7575/5/Tese\%20\%20Poliane\%20Vieira\%20Nogueira\%20-\%202017.pdf>. Acesso em: 04 jul. 2018. 
ROJO, Roxane. Pedagogia dos Multiletramentos: diversidade cultural e de linguagens na escola. In: ROJO, R.; MOURA, E. Multiletramentos na escola. São Paulo: Parábola Editorial, 2012. (Estratégias de Ensino, 29.)

SOUSA, Sandra Lopes. Construindo uma comunidade de leitores: seleção de obras e estratégias de leitura literária. (Dissertação. Mestrado). Programa de Mestrado Profissional em Letras - ProfLetras. Universidade Federal de Uberlândia: Minas Gerais, 2016. Disponível em: $<$ https://repositorio.ufu.br/bitstream/123456789/18427/1/ConstruindoComunidadeLeitores.pd f.. Acesso em: 04 jul. 2018.

STREET, B. Letramentos sociais: abordagens críticas do letramento no desenvolvimento, na etnografia e na educação. Tradução: Marcos Bagno. São Paulo: Parábola, 2014.

VEYNE, Paul. Foucault: seu pensamento, sua pessoa. Rio de Janeiro: Civilização Brasileira, 2014.

Recebido em: 10/02/2019

Aceito para publicação em: 16/03/2019 